Please send trade news information and

illustrations to Arveen Bajaj at the $B D J$, Nature

Publishing Group, The Macmillan Building,

4-6 Crinan Street, London N1 9XW.

Trade news is provided as a service to readers

using text and images from the manufacturer,

supplier or distributor and does not imply

endorsement by the BDJ. Normal and prudent

research should be exercised before purchase or

use of any product mentioned.

\section{New rotating toothbrushing launched}

Twist ' $n$ ' Brush is an innovative new toothbrush that rotates through 360

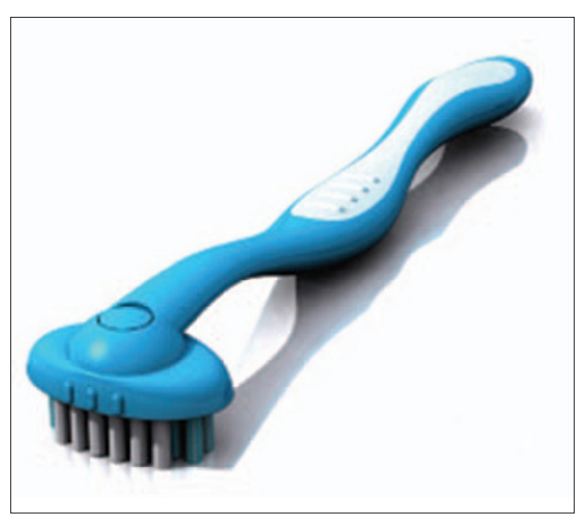

\section{Lifetime price freeze}

DentalPlus announces a lifetime price freeze on its professional practice management system. With DentalPlus the annual license incorporates full use of the software, installation, initial training package, all telephone assistance and remote access help. You lock into the price at the time the contract is signed; subsequent charges are then held at that rate, effectively decreasing real costs year on year. degrees, adjusts to the curvature of your mouth, and makes brushing the right way and in the right places easier and more effective than a conventional toothbrush.

Twist ' $n$ ' Brush helps the user to follow dental advice but does not require them to radically alter their brushing habits. Twist ' $n$ ' Brush also makes it easer to brush the tongue and inner cheek areas - helping to remove the bacteria that causes bad breath. It is currently being distributed throughout the UK and HD Products are also developing different versions of Twist 'n' Brush.

Reader response number 50

Unlike other systems, DentalPlus future-proofs your practice by incorporating all new versions and all updates to the software whilst the license remains in force. Additionally DentalPlus runs a developer program where you are able to suggest changes or improvements, or just practice-specific software requests. These are developed in conjunction with you, then released to the whole DentalPlus community without charge.

Reader response number 51

\title{
No artificial sweeteners or flavourings
}

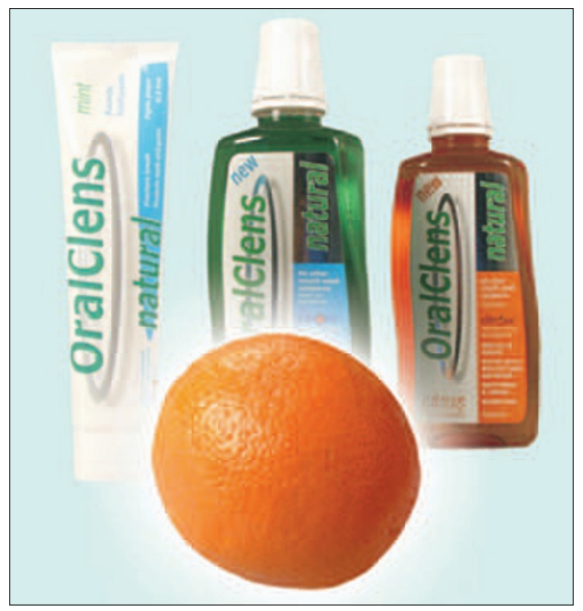

Oralclens toothpaste from Oraldent is not only SLS free, it contains no triclosan, CPC, artificial sweeteners or flavourings.

The antibacterial action of OralClens is produced by a natural mixture of non toxic bioflavinoids and fruit acids called Citroxx.

For patients who do not require a chlorhexidine-based product and who wish to enhance their oral health care experience, OralClens also offers an alcohol free mouthwash in a citrus or mint flavour which ideally complements the toothpaste.

Reader response number 52

\section{Greener surgeries}

The UK dental industry can reduce personal contribution to global warming and set an example according to CareCapital, a developer of dental premises. Specialising in everything from allocating your ideal site, planning and financing, right through to design, construction and facilities management, it ensures its developments address the green agenda at every opportunity.

Typical design and architectural considerations involve maximising the use of natural light, insulation, double glazing and the use of materials and building methods which reduce energy demands during construction.

Reader response number 53

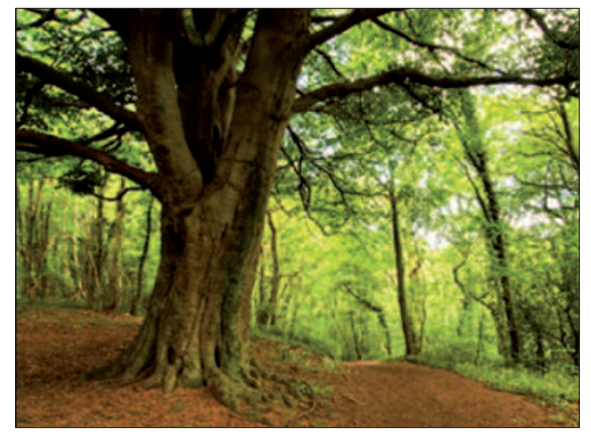

\section{Remove stains gently}

Air polishing is indicated for use on extrinsic stains left by coffee, red wine and certain food and is accomplished by the use of a mild polishing agent such as the Jet-Fresh.

Carried by a stream of air and water to gently remove stain, Jet-Fresh is not sodium bicarbonate-based, and so provides improved equipment reliability and easier maintenance.

The latest model is the Cavitron Jet Plus, a 2-in-1 ultrasonic scaler and air polisher, making it the cost-effective choice for your practice. To help you promote your air polishing service to your patients, Dentsply provides free of charge promotional postcards to Cavitron customers. Reader response number 54 


\section{Dental technology}

Evident's new collection of dental technology includes a digital dental radiograph system, video X-ray film viewer and capture, an intraoral camera, cordless curing light and an automatic alginate mixer.

All offer benefits to help keep your practice up-to-date with the latest dental technology. Evident's expert product consultants are also on hand to offer pre and post sales support and advice.

Reader response number 55

\section{High quality imaging}

Digital Dental believes that high quality digital imaging is a cornerstone for successful private practice. The company can provide unbiased advice to enable dentists to choose the right products for their individual digital imaging needs.

They appreciate every practice is different and has individual requirements. Therefore they offer a range of options, enabling their clients to make the best choice for them in order to integrate the latest and most appropriate digital tools into their practices.

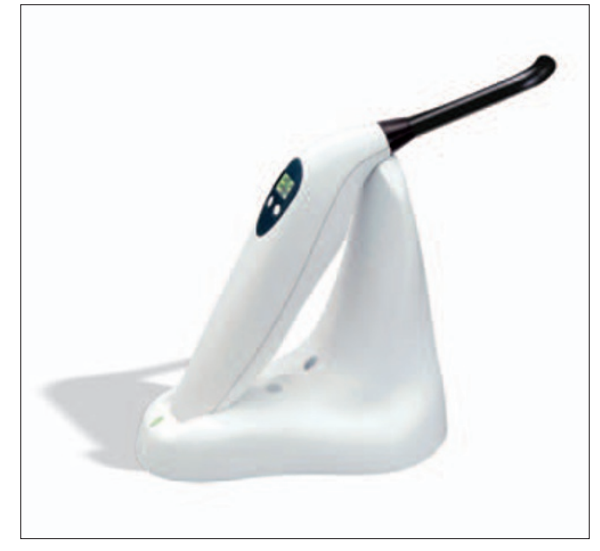

They can supply the best products on the market, which can integrate with any practice management software to deliver seamless integration and paperless practices.

Their technically trained advisers demonstrate, install and train their clients on the selected equipment; ensuring they get exactly what they were promised.

Digital Dental can demonstrate everything at one visit and at times to suit the practice and then install the equipment and provide comprehensive free hardware and software training.

Reader response number $\mathbf{5 6}$

\section{Durability and scratch resistance}

NSK's high-quality affordable turbines and contra-angles from the Ti-Max X Series offer benefits in terms of speed and precision, delivering powerful cutting when you need it most and enabling

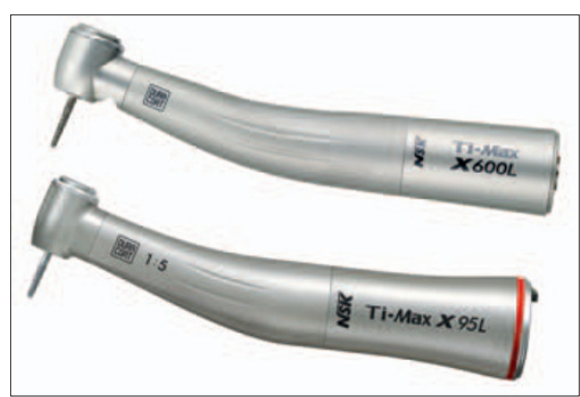

you to meet the clinical and aesthetic demands of your patients.

The X Series features the latest technology yet combines elegance with ergonomic design. These include Dual Air Jets which produce unmatched levels of power and performance and NSK's most recent advancement, Duracoat, a surface treatment to optimise durability and scratch resistance.

Both of these features enable you to carry out procedures with speed, confidence and accuracy and have the assurance of a two year guarantee on both turbines and contra-angles.

Reader response number 57

\section{Treatment plans simplified}

At a time when many practitioners are considering making the move towards private dentistry, one of the areas that may cause difficulties is explaining the treatment plan effectively and efficiently to patients.

First Media Dental has a powerful, workable solution with the CameRom Patient Information System and Practice Marketing Solution. The X-ray library can help inform patients of their own dental conditions by showing comparative annotated radiographs. For example, the annotated periodontal X-rays clearly show your patients healthy bone levels and actual reduced bone levels, sharply and clearly enabling you to explain treatment plans to your patients that may otherwise be difficult for them to comprehend.

The CD is operated through your computer and is a chairside treatment demonstration system that shows actual cases, close up, rather than animated illustrations. You can talk your patients through a range of 28 video real-life treatments, such as tooth whitening, composite fillings, veneers, crowns etc, whilst they are in the chair, allowing patients to make an informed choice of the treatment options available. You may choose to print off the selected photograph and keep it in the patient's notes for more accurate record keeping.

Reader response number 58

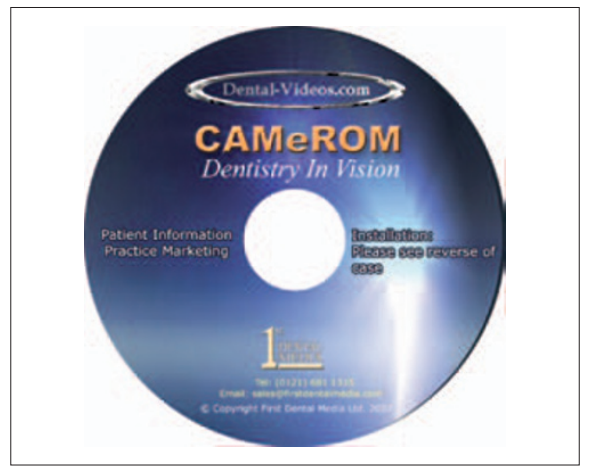




\section{Programmable procedures}

The QuickWhite Lase soft tissue diode laser from DMDS is a small affordable soft tissue tactile diode laser which can replace electrosurgery and for the hygienist, gum management procedures can be carried out quickly and easily.

With touch screen pre-set procedures and user programmable procedures the QuickWhite Laser had a built in battery pack to allow complete versatility. Weighing just over $1.13 \mathrm{~kg}$ it is small enough to fit into a briefcase making it easy to move from surgery to surgery.

It features applications ranging from gingivectomy and crown lengthening to laser curettage and operculectomy. The laser is directed through a jacketed glass clad silica fibre and both this and the handpiece are fully autoclaveable for complete sterilisation.

\section{Heat-treated burs}

Dentsply range of Diamond and Steel burs are heat-treated to 750 on the Vickers hardness scale (enamel is 300), for excellent cutting efficiency. HiDi Diamond Burs are manufactured with precision made shanks

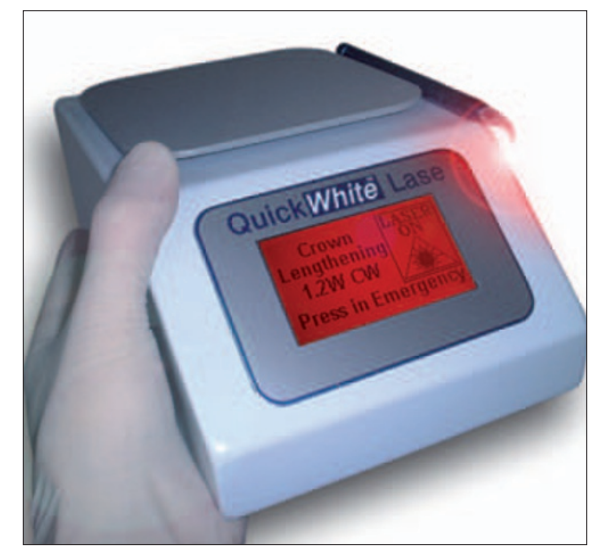

With a wavelength of $810 \pm 5$ nanometers and 0.1-3 watts of power, you can choose from either continuous wave or pulsed depending upon your chosen application. These include soft tissue management, gingival incisions and excisions, second stage recovery of implants and vestibuloplasty.

Reader response number 59

and carefully applied and inspected diamond layers, to ensure the longevity of both the bur and your handpiece.

The high standards of 100\% inspection remove any defective burs and multiple diamond layers.

Reader response number 61

\section{Single-patient use disposable syringes}

Septodont's Ultra Safety Plus XL needles are sterile, single-patient use, disposable safety syringes which have a sliding sheath to guarantee maximum safety against needle stick injury for all users.

The single use nature of this product gives both you and your patients complete peace of mind when it comes to cross infection control. Septodont disinfection range includes medical devices, manual instruments and equipment, right through to mouthwashes, spray-on skin antiseptic and protective hand cream.

Reader response number 60

\section{Financial advice}

money4dentists is a specialist independent financial adviser (IFA) and can exclusively advise dentists or partners of dentists in financial matters. The IFA can help you to identify your objectives and priorities and guide you towards a practical, straightforward strategy to achieve your goals.

Matters such as residential mortgage or practice loan, private medical insurance, bank accounts, tax efficient savings,

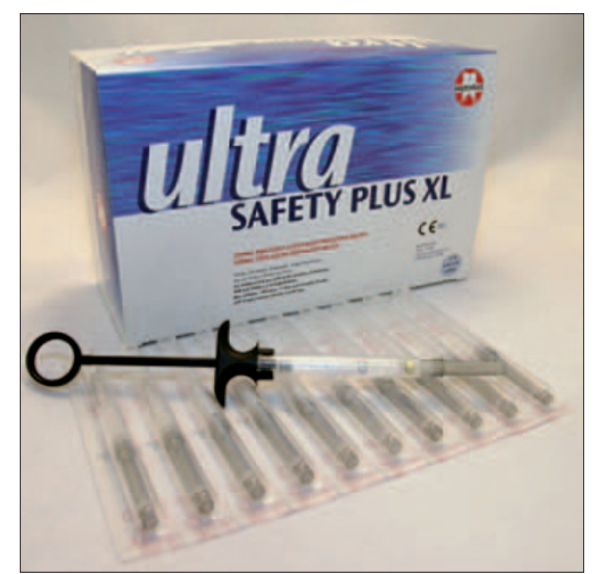

NHS Pension Scheme Forecasts, private pension forecasts, education plans or ensuring current investment funds reflect your current attitude to risk, are all key things a financial adviser can assist you with.

They will check your complete financial situation, suggest a suitable financial strategy and then comb the entire market for the best financial products available to fit your specialist needs as a dentist.

Reader response number 62 